\title{
El mito de Sísifo: los límites de la política exterior libanesa
} The Myth of Sisyphus: the limits of Lebanon's foreign policy

\author{
Julio SEVILLA MORENO \\ Institut d'Études Politiques (Aix-en-Provence) \\ juliosevillamoreno96@gmail.com \\ https://orcid.org/0000-0003-0795-8652 \\ Recibido 18/05/2021. Aceptado 30/11/2021
}

\begin{abstract}
Para citar este artículo: Julio SEVILLA MORENO (2021): "El mito de Sísifo: los límites de la política exterior libanesa" en Revista de Estudios Internacionales Mediterráneos, 31, pp. 218-243.
\end{abstract}

Para acceder a este artículo: https://doi.org/10.15366/reim2021.31.011

\section{Resumen}

Con el fin de la ocupación siria en 2005 al Líbano se le presenta el reto de definir su política exterior. Un sistema confesional que crea profundas divisiones a la hora de tomar decisiones a nivel diplomático, un poder regional que no cesa de polarizarse y la influencia de actores externos provoca sin embargo una parálisis crónica en un Estado que ve cómo todo conflicto externo lo afecta sin quererlo. Ante esta situación, el Líbano aplica una política exterior de supervivencia, llamada de "neutralidad positiva" y de "disociación" años más tarde, en un intento de evitar que los partidos políticos que representan al Estado lo vuelvan a sumergir en una nueva guerra civil.

Palabras clave: Disociación, neutralidad positiva, behavioralism, confesionalismo, soft power

\begin{abstract}
With the end of the Syrian occupation in 2005, Lebanon was challenged to define its foreign policy. However, a confessional system creating deep divisions within the decision-making process at diplomatic level, an increasingly polarised regional power, as well as the interference by foreign actors have caused the State to be chronically paralysed. Aware of the impact on the country of any regional conflict, Lebanon applies a foreign policy aimed at survival, years later called "positive
\end{abstract}


neutrality" and "dissociation", in an attempt to prevent the political parties that represent the State from plunging the country into another civil war.

Key words: Dissociation, positive neutrality, behavioralism, confessionalism, soft power.

\section{Introducción}

Implementar una política exterior eficaz se ha convertido en un auténtico rompecabezas para las autoridades libanesas en los últimos años. En 1975 Líbano se veía inmerso en una fratricida y despiadada guerra civil que duraría 15 años y desembocaría en una ocupación a modo de "tutela" por parte de la vecina Siria. En 2005 es asesinado el entonces primer ministro (PM) libanés Rafiq Hariri, y si bien la autoría del atentado no es reconocida por el ocupante sirio, buena parte de la sociedad civil libanesa sale a las calles el 14 de marzo para exigir la retirada de las tropas y el fin de la ocupación a todos los niveles. La manifestación, a la que acuden un millón de personas (Picard, 2008: 93), se suma a un clima de presión internacional amparado en la Resolución 1559 del Consejo de Seguridad que, en septiembre de 2004, exigía la retirada de las tropas extranjeras del territorio libanés, así como el desarme de sus milicias (UN, 2004).

El ostracismo internacional al que se precipitaba inevitablemente Siria con el mantenimiento de su ocupación del Líbano era de sobra conocido por el régimen de Assad, quien horas antes del atentado contra Hariri, en un encuentro con el entonces ministro de Asuntos Exteriores (AAEE) español, Miguel Ángel Moratinos, afirmaba que la influencia siria sobre Líbano continuaría incluso después de abandonar el país (Choucair, 2006). El asesinato del PM libanés podría interpretarse entonces como una última acción directa para acallar una voz disonante, influyente y con mucho poder en el país del Cedro. Como han demostrado de forma exhaustiva autoras como Elizabeth Picard (Picard, 2016) o Marta Tawil Kuri (Tawil, 2016) la influencia siria continuó y continúa aún hoy, a todos los niveles, en el Líbano.

El paisaje político post-ocupación quedaba sin embargo polarizado entre los considerados como aliados de Siria, que el 8 de marzo celebraban una manifestación de agradecimiento al país vecino, y sus detractores, que organizaron la ya mencionada anteriormente y más multitudinaria seis días más tarde. Los bloques del 8 y del 14 de marzo nacían con la retirada de Siria del Líbano, y los partidos políticos se adscribían voluntaria o involuntariamente a uno u otro bando ${ }^{1}$. Con el nuevo escenario de aparente soberanía urgía definir una política exterior que dotara al Líbano de cierta presencia regional en un Oriente Medio que atraía todos los focos internacionales.

\footnotetext{
${ }^{1}$ Cabe destacar en este sentido las declaraciones de Michel de Chadarevian, responsable de Relaciones Diplomáticas del Movimiento Patriótico Libre (principal partido político cristiano del Líbano), y consejero diplomático del actual PR, Michel Aoun. El Movimiento Patriótico Libre había liderado la oposición en territorio nacional y en el exterior contra la ocupación siria, pero, al establecer una alianza política con Hezbollah en 2006, pasó a pertenecer al bloque del 8 de marzo en contra de su voluntad. En una entrevista con el autor a fecha de 20 de enero de 2020 Michel de Chadarevian afirma: "Por hacer el 'memorandum of understanding' con Hezbollah, que estaba con ellos en el mismo Gobierno, con el que habían ido de la mano a las elecciones, nos dijeron que pertenecíamos al 8 de marzo. Pero el 14 de marzo, queridos amigos, lo hemos hecho nosotros. Nosotros no somos 8 de marzo." (Michel de Chadarevian, comunicación personal, 20 de enero de 2020)
} 
Si bien se conseguían acuerdos entre partidos pertenecientes a bloques enfrentados para legislar a nivel nacional, la política exterior seguía siendo una fuente de conflictos. La "neutralidad positiva" que acaba adoptando el ejecutivo libanés en 2005 no difiere de la política exterior del país los años anteriores, cuando se define como de "neutralidad" en el período preguerra y de "concomitancia de los procesos libaneses y sirios y su destino común" durante la ocupación siria (Karam, 2012: 186). Más que la aceptación y el consenso alrededor de la idea de neutralidad supone una fórmula que permite al Estado libanés no tomar posición a nivel regional e internacional, mientras los partidos que lo conforman tienen total libertad para alinearse con potencias regionales y establecer relaciones que rozan la dependencia ${ }^{2}$. Con el estallido de las revoluciones árabes el Estado adopta la disociación de los conflictos regionales, que persigue el mismo objetivo, pero a diferencia de la neutralidad positiva encuentra un consenso casi total entre el conjunto de las fuerzas políticas libanesas.

La hipótesis del artículo afirma que la diplomacia libanesa no respeta la neutralidad positiva ni la disociación a causa del propio sistema confesional y de una polarización regional que provoca estrategias políticas variadas en el seno del ejecutivo. El objetivo principal de este artículo es, por tanto, el de demostrar en qué medida un Estado como el libanés es capaz de cumplir con las políticas de neutralidad positiva y de disociación. Para ello, se observa la política exterior del Líbano desde la retirada siria hasta la actualidad y los diferentes conflictos y luchas de poder que tienen lugar a la hora de implementarla.

Si bien la política exterior del Líbano desde 2005 constituye el principal objeto de estudio del artículo, esta no se puede comprender sin el análisis de dos elementos principales que aparecen de forma recurrente a lo largo del trabajo. Por un lado, el sistema político confesional libanés y sus consecuencias en el proceso de toma de decisiones en política exterior. Por el otro, el conjunto de alianzas, estrategias o posturas que adoptan los partidos políticos libaneses que ostentan cargos clave a nivel diplomático. En lo que respecta al marco teórico de las Relaciones Internacionales utilizado para el análisis de la política exterior libanesa se aplica el modelo burocrático de Graham Allison (1971). El modelo que este autor propone, enmarcado en la corriente del behavioralism, permite comprender las características del sistema consociativo o confesional y analizar los intereses de los distintos partidos políticos libaneses que disponen de capacidad ejecutiva en política exterior.

La primera parte del trabajo se centra por lo tanto en el estudio de dos elementos centrales. Por un lado, la comprensión de las características del confesionalismo libanés y las consecuencias de dicho sistema en el proceso de toma de decisiones en política exterior. Por el otro, y en paralelo, se observa el modelo burocrático de Graham Allison que, dentro de la disciplina de las Relaciones Internacionales, se considera más pertinente para la correcta comprensión de la política exterior libanesa. Una vez analizados tanto el confesionalismo como el marco teórico utilizado se procede a observar la cronología de eventos que afectan al equilibrio de poder político y a la política exterior libanesa, desde 2005 hasta la actualidad. La segunda parte del trabajo se centra en los primeros años de la política exterior libanesa, de 2005 a 2014, cuando el país atraviesa varias fases de inestabilidad y los distintos ministros de AAEE son personalidades chiís respaldadas por los dos partidos políticos más representativos de esta confesión, Hezbollah y Amal. En esta primera sección se elabora una breve introducción sobre el equilibrio de poder político, los conceptos de neutralidad positiva y disociación y los primeros conflictos de intereses a nivel diplomático. Más tarde, se hace un análisis de los límites y contradicciones del concepto y aplicación de la disociación, observando

\footnotetext{
${ }^{2}$ Es el caso de Hezbollah con Irán, del que depende financiera y armamentísticamente y en menor medida el del Movimiento del Futuro con Arabia Saudí.
} 
a su vez la influencia de Arabia Saudí e Irán en el Líbano. En la tercera sección del trabajo se estudia la política exterior desde 2014 a raíz del relevo de poder que se produce en la diplomacia libanesa, entendiendo las nuevas estrategias y acciones implementadas en un contexto regional y nacional frágil y en constante cambio. Para finalizar, se analizan las dificultades que atraviesa el Líbano en la actualidad, se elaboran una serie de conclusiones sobre la política exterior libanesa desde 2005 y se comprueba si la hipótesis del trabajo es acertada o errónea.

El artículo se apoya en una serie de entrevistas que el autor realiza en los primeros meses de 2020 a una serie de expertos economistas, políticos y académicos en el Líbano. Destacan entre las personalidades políticas los miembros y disidentes del partido cristiano Movimiento Patriótico Libre (MPL), teniendo en cuenta que, de 2014 a 2020, los representantes de dicho partido ostentan el Ministerio de Asuntos Exteriores y, desde 2016, la Presidencia de la República libanesa.

\section{Confesionalismo político y marco teórico}

El Líbano posee un sistema político confesional o consociativo, en el cual el Gobierno está formado por élites de distintas comunidades (Lijphart, 1969: 216). Las democracias consociativas se caracterizan por ser proporcionales con las distintas comunidades a nivel electoral en la distribución de puestos en las instituciones y en los recursos del Estado (Andeweg, 2000: 512). Los cristianos, musulmanes sunís y musulmanes chiís son las tres principales confesiones o comunidades presentes en el Líbano, y el reparto de poder a nivel institucional es equitativo para las tres partes. Estos tres grupos están representados a su vez por varios partidos políticos.

El Gobierno libanés está compuesto por los diferentes ministros y ministras representantes de un partido político relevante a nivel nacional, si bien existe una cuota presidencial que elige el presidente de la República (PR) y varía, según el caso, entre tres y cinco ministros. Este último ha de ser cristiano, mientras que el PM ha de ser suní y el presidente del Parlamento chií. Como lo demuestra la disposición del Gabinete ministerial, los partidos políticos relevantes tienen representación y forman parte del Gobierno. En la etapa post- ocupación que se analiza en este trabajo el Gabinete ministerial cuenta con entre 15 y 30 ministros según el Gobierno, elegidos por el PM y aceptados por el conjunto de los parlamentarios por mayoría simple. Dichos parlamentarios son también los encargados de elegir al PR. Tanto este último como el PM y en menor medida el presidente del Parlamento y los ministros tienen capacidades ejecutivas, pero la necesidad de consenso aparece de forma recurrente.

La Constitución Libanesa especifica en su artículo 65.5 del Título II que las "cuestiones fundamentales" relativas a, entre otras, las reformas de la Constitución, los presupuestos del Estado, los acuerdos internacionales, la guerra y la paz o la reforma de la ley electoral necesitan de la aprobación de dos tercios de los ministros (Constitución del Líbano, 1990: 11). De igual forma, la dimisión de 11 ministros de los 30 presentes en el ejecutivo provoca automáticamente la disolución del Parlamento y obliga a formar un nuevo Gobierno. La necesidad de consenso en un contexto de polarización política regional, donde cada partido defiende intereses y perspectivas distintas, explica los desacuerdos en la política exterior y de Defensa del país del Cedro. Ello no impide, sin 
embargo, que los miembros de la diplomacia libanesa se expresen libremente y tomen partido y decisiones de forma unilateral a nivel regional e internacional, pese a las rivalidades y conflictos que les puedan provocar a nivel nacional dichas acciones.

Este sistema político tiene sus cimientos en un conjunto de relaciones sociales que se dan entre los líderes políticos y religiosos y los miembros de la comunidad o electores. La identidad comunitaria o confesional está muy arraigada en la sociedad libanesa, ya que dichos líderes comunitarios y religiosos son los que se encargan de proporcionar los recursos a los miembros más desfavorecidos de su comunidad (Kochuyt, 2004: 525-530). En un Estado poco intervencionista e incapaz de garantizar una serie de servicios mínimos para el conjunto de la población son dichas comunidades las que adquieren o intentan adquirir el rol de Estado. Buen ejemplo de ello son los servicios sociales y securitarios que Hezbollah ofrece en los barrios del sur de Beirut y en el valle de la Beqaa, los que garantiza de igual forma el Movimiento del Futuro en barrios de Trípoli, Sür o Sayda, o programas como el de las "8 naranjas" del MPL, que ofrecía descuentos en supermercados y farmacias a la población cristiana, entre otros ejemplos. De esta forma, el porcentaje de población que depende de los recursos que la comunidad les proporciona entiende la supervivencia de su comunidad como la propia. La comunidad como garante de recursos provoca necesariamente que las lógicas de pertenencia sean mayores, y que el elector beneficiado devuelva el favor a través del voto.

Para mantener esta relación con respecto a los miembros de la comunidad que los mantiene en una posición de poder, las élites políticas y religiosas necesitan ciertos recursos que se buscan, por lo general, en el extranjero. Las alianzas que establecen ciertos partidos políticos libaneses a nivel regional tienden de esta forma a satisfacer los intereses de sus élites, más centradas en perpetuar su poder en la comunidad y a nivel nacional que en defender los intereses del Estado libanés. En este sentido, son de sobra conocidas y documentadas las relaciones de Irán con Hezbollah (Norton, 2014) o las de Arabia Saudí con el líder del Movimiento del Futuro (MF) Saad Hariri (Vloeberghs, 2012). Es de igual forma ilustrativa la filtración por parte de Wikileaks de los "Saudi cables" en 2015, que mostraban al líder del partido cristiano Fuerzas Libanesas, Samir Geagea, pedir financiación a Arabia Saudí a cambio de "hacer todo lo que el reino pida" (Hubbard, 2015), lo que evidencia la situación de precariedad financiera de los partidos políticos locales y la facilidad para los actores externos de influir en la política nacional. Existe por tanto una contradicción entre la voluntad de implementar una política exterior definida en un Estado que se rige por el consenso y la propia naturaleza del sistema político, donde existen varios centros de poder y donde cada actor establece alianzas exteriores diferentes y, en ocasiones, opuestas.

Para comprender esta contradicción y, teniendo en cuenta las particularidades del sistema político libanés, es necesario aplicar un modelo teórico dentro de la disciplina de las Relaciones Internacionales capaz de explicar la política exterior libanesa y su implementación. En este trabajo se observará el modelo burocrático de Graham Allison, ya que es el que más elementos de respuesta ofrece a la hora de estudiar la política exterior. Este autor se enmarca dentro de la doctrina behavioralista, que nace con la intención de cuestionar la metodología que se venía aplicando en las Ciencias Políticas y las Relaciones Internacionales a la hora de explicar fenómenos políticos. Los behavioralistas pretendían desarrollar una metodología científica y cuantitativa para comprender dichos fenómenos, inspirándose en los métodos que se venían aplicando en las ciencias sociales y matemáticas (Hamati-Ataya, 2019: 1). Aplicado a las Relaciones Internacionales, supuso una revolución en cuanto a la introducción de nuevos modelos que se centraban en analizar fenómenos concretos, como el análisis de la política exterior o la interdependencia (Halliday, 1994).

Perspectivas de elección racional como la teoría de juegos o el proceso de toma de decisiones ganan aceptación y son cada vez más utilizados en la disciplina de las Relaciones Internacionales (Abou Samra, 2021: 6). Con el empirismo como guía, los defensores del behavioralism afirman que existe 
una relación entre las variables de carácter doméstico y la política exterior, algo que desde el realismo clásico se negaban a aceptar, pensando que el interés nacional era independiente y común a todos los miembros del ejecutivo. Según esta crítica, los gobernantes pueden actuar a nivel internacional para satisfacer objetivos nacionales o regionales (Jordán, 2013: 33).

Si el ejecutivo encargado de dirigir la política exterior está a su vez formado por varios individuos o grupos de personas con intereses contrapuestos sería lógico pensar que va a existir un conflicto constante a la hora de desarrollar la política exterior. Es aquí donde el modelo teórico que ofrece Graham Allison sirve para explicar el caso libanés. Este "modelo burocrático" parte de la base de que la toma de decisión es un proceso del que participan varias personas. La política exterior es, por lo tanto, el resultado de una negociación en el seno de la administración entre entes individuales y colectivos que intentan orientar esta política pública según sus percepciones e intereses (Allison, 1971, en Gourrada, 2013: 36). En el caso del ejecutivo libanés la política exterior se coordina entre el ministro de AAEE, el PM que guía la política del Gobierno y el PR (Gourrada, 2014: 35).

El modelo teórico de Graham Allison, enmarcado en la corriente del behavioralism, permite comprender dos elementos principales de la política exterior libanesa. El primero es la existencia de una correlación entre las esferas nacionales e internacionales, y la comprensión de las consecuencias que las decisiones que se toman en cualquiera de ellas tienen en la otra. Por otro lado, la división del poder estatal en varias parcelas y no como un ente indivisible con voluntad autónoma. Cada confesión o comunidad representada por un partido político ocupa una parte de poder y se relaciona a nivel internacional de la forma que cree adecuada. Varios actores participan del ejecutivo encargado de representar al Estado libanés en sus Relaciones Internacionales. La política exterior libanesa no es más que el resultado de la negociación de dichos actores y de sus luchas de poder. Por ello, es necesario saber en todo momento quién toma las decisiones en política exterior y observar si los intereses que satisface son los de su propio partido o comunidad, o bien los del Estado libanés.

\section{Los primeros años de la era post-ocupación: redefinición del espacio político y primeras luchas de poder}

La política regional a principios de siglo no se encontraba tan polarizada como en la actualidad. La lucha por la hegemonía entre Irán y Arabia Saudí no acaparaba todos los focos en una región testigo de la Segunda Intifada, de las invasiones de Afganistán y más tarde de Iraq por parte de los EEUU o de la pérdida de poder de una Siria todavía protagonista. Sin embargo, se comenzaban a vislumbrar ciertas señales de la futura enemistad que marcaría el equilibrio de poder y los conflictos venideros en Oriente Medio. Ya a finales de 2004 personalidades como el rey Abdallah II de Jordania, el ministro de AAEE saudí Saud al-Faysal o el presidente egipcio Hosni Mubarak alertaban de la creciente influencia de Irán y el aumento de población chií en la región (Rabi, 2009: 189). La guerra de Hezbollah contra Israel en 2006 no haría más que afianzar esta visión del chiísmo como amenaza, disfrazando de religioso un enfrentamiento puramente político. La escalada de tensiones era palpable, como lo demuestran las fatawas (فتاوى) pronunciamientos oficiales de ulemás wahabitas denunciando la herejía del chiísmo, o las acusaciones del Ayatolá Khomeini hacia los Estados sunís 
del Consejo de Cooperación del Golfo como "marionetas corrompidas de los americanos" (Ibid). Los partidos políticos libaneses se alinean en su mayoría con uno u otro bando siguiendo esta lógica de poder regional. Mientras el bloque del 8 de marzo se alineaba con el eje sirio-iraní el bloque del 14 de marzo compartía la estrategia regional de países árabes bajo influencia de los EEUU, como Arabia Saudí, Egipto o Jordania (Salloukh, 2008: 309). La lucha de poder que se libraba a nivel regional afecta al Líbano, que no encuentra el consenso necesario para desarrollar una Estrategia Nacional de Defensa que garantice la seguridad del territorio tras la retirada siria. En este contexto de impasse, el presidente del Parlamento Nabih Berry convoca en 2006 un Foro de Diálogo Nacional (Wählisch, 2017: 7). Buen ejemplo de la falta de consenso en este campo es la Cumbre de la Liga Árabe de 2006 celebrada el 29 de marzo en Jartoum (Sudán), donde el Líbano envía dos delegaciones, una representada por el PR Émile Lahoud y la otra por el PM Fuad Siniora. En dicha Cumbre se inicia un conflicto acerca del carácter de "Resistencia" de Hezbollah entre las dos delegaciones libanesas. El propio Parlamento libanés remite una carta firmada por una mayoría de parlamentarios donde se pone en duda la legitimidad del PR Lahoud, que defendía el mantenimiento de armas del partido-milicia chií (Young, 2006). La doble delegación diplomática estará de nuevo presente en la Cumbre del año siguiente celebrada en Riad (Arabia Saudí).

El debate sobre el armamento de Hezbollah y el carácter de las relaciones a establecer con el antiguo ocupante sirio suponen los principales obstáculos que separarán a los bloques del 8 y del 14 de marzo. La Resolución 1559 aprobada por el Consejo de Seguridad de la ONU del 2 de septiembre de 2004 exigía la retirada de las tropas sirias y el desarme de las milicias que operaban en el país. La organización chií mantuvo sin embargo su armamento justificando la necesidad de protección ante Israel, con el que estaban en guerra y que seguía ocupando parte del territorio libanés, Las Granjas de Shebaa, al sur del país. Mientras el bloque del 8 de marzo defendía la necesidad de establecer una "Resistencia" ante Israel los partidos del bloque del 14 de marzo criticaban que el monopolio de la violencia no perteneciera al Ejército Libanés en su totalidad, conscientes de la influencia que Irán ejercía en la organización chií libanesa. En mayo del 2008 la tensión aumenta en el país del Cedro. Fuad Siniora decide cortar la red de comunicación privada de Hezbollah, algo que la organización chií entiende como un ataque, y a lo cual responde ocupando militarmente el Oeste de Beirut y una parte de la montaña (El-Ezzi, 2008: 70). Este episodio, que desembocaría en los acuerdos de Doha con mediación francesa, siria, catarí y saudí, alteraría el equilibrio de poder en el Líbano y daría un mayor protagonismo al bloque del 8 de marzo.

Los problemas nacionales libaneses ocupan hasta el año 2008 un papel central y son objeto de debate en las Cumbres de la Liga Árabe. La diplomacia libanesa se encuentra, como el país, frontalmente dividida, por lo que resulta muy difícil adoptar una postura común para tratar los problemas que los países árabes sufren en estos años. Esto, sin embargo, empieza a cambiar en 2009, tras la estabilidad institucional que provocan los acuerdos de Doha, la llegada de Michel Sleiman a la presidencia y la entrada del Líbano en el Consejo de Seguridad de la ONU como miembro no permanente. El Líbano participa de una Cumbre económica en Kuwait para paliar los efectos de la crisis económica, envía esta vez una sola delegación a la Cumbre de la Liga Árabe, y acoge en Beirut un Foro árabe para crear estrategias regionales que aborden el problema del trabajo. Este papel más protagonista a nivel diplomático es posible gracias a la relativa estabilidad que conoce el país con el ejecutivo de "unidad nacional" que forma Saad Hariri, PM, presidente del MF e hijo de Rafiq Hariri. Pero la voluntad diplomática no implica necesariamente posicionamiento político, algo que la diplomacia libanesa cuidaría desde el principio. El Líbano se abstendría en votaciones del Consejo de Seguridad de la ONU, evitando de esta forma bloquear decisiones (Karam, 2012: 187) sin tener que posicionarse en el debate. De igual forma, en junio de 2010, se abstiene de votar la Resolución 1929 que imponía nuevas sanciones a Irán. 
La neutralidad positiva libanesa derivaría, en un contexto de revoluciones árabes, en una disociación de los conflictos regionales. En agosto de 2011 el PM declaraba querer "poner un muro entre lo que pasa en Siria y sus implicaciones para Líbano" (L'OL, 17/8/2011). Un año más tarde, en junio de 2012 y una vez que el conflicto en Siria derivaba hacia la guerra civil (AFP, 16/7/2012), los partidos políticos libaneses firmaban la Declaración de Baabda y oficializaban la célebre disociación.

\section{La política de disociación libanesa: límites y contradicciones}

El año 2011 supone un punto de inflexión para los regímenes autoritarios en los países árabes. Inspirados en las revoluciones tunecinas y egipcias, las sociedades árabes comienzan una serie de movilizaciones y protestas para exigir, si no un cambio en las élites gobernantes, por lo menos una mejora en las condiciones económicas y de libertades políticas de la población. Se produce un efecto dominó en países como Bahréin, Jordania, Libia, Marruecos, Omán, Siria y Yemen, si bien con distinta intensidad $y$, sobre todo, con diferentes consecuencias (Camau, 2012: 28). Cuando comienza la represión violenta de manifestaciones pacíficas por parte del régimen de Assad el espectro político libanés se polariza aún más. El bloque del 14 de marzo, y el suní Movimiento del Futuro en concreto, aparecen como los defensores de un movimiento popular, democrático y no sectario. Sin embargo, el bloque del 8 de marzo parece defender un régimen represivo y autoritario (Vloeberghs, 2012: 246).

A nivel diplomático el Líbano sigue en la línea de una neutralidad positiva que evolucionará, por lo menos en cuanto al nombre, en disociación de los conflictos regionales, absteniéndose de votar tanto en el Consejo de Seguridad de las Naciones Unidas como en la Liga Árabe. El Representante del Líbano en el Consejo de Seguridad era Nawaf Salam, un reputado jurista defensor de la política de disociación e impulsor del Tribunal Especial para Líbano encargado de juzgar el asesinato de Rafiq Hariri. No cede a las presiones de Hezbollah, pero no por ello pertenece a ningún partido del bloque del 14 de marzo. En los dos años en que el Líbano pertenece al Consejo de Seguridad como miembro no permanente se abstiene de votar no solo en las Resoluciones o Declaraciones que tengan que ver con Siria, sino también con Irán. En junio de 2010, por ejemplo, decide abstenerse en la Resolución 1929 que imponía nuevas sanciones al Estado persa. Cuando comienza la represión violenta de las manifestaciones en Siria, el Consejo de Seguridad condena las acciones de Assad en votaciones de agosto y octubre de 2011, y el Líbano se sigue absteniendo.

En el caso de la Liga Árabe el representante es el ministro de AAEE Adnan Mansour, perteneciente al partido chií Amal, aliado histórico de Siria, sobre todo durante la guerra civil (Norton, 2007: 477) y en menor medida, de Irán. La disociación se incumplirá por primera vez en una polémica votación el 12 de noviembre de 2011 para expulsar a Siria de la Liga Árabe. En esta votación la delegación libanesa votó en contra en lugar de abstenerse, poniendo en duda la validez de un concepto que solo podía respaldarse con abstenciones en foros regionales e internacionales. En este caso Adnan Mansour, miembro del partido Amal, alineado regionalmente con el eje sirio-iraní, explicaba que la decisión tendría un "impacto negativo en el proceso de paz y en la estabilidad regional" (Mansour, en Taghrib News, 15/11/2011). Según el ministro el voto en contra se justificaba como un intento de mantener la estabilidad de la región y por tanto del Líbano. Pese a que la directiva de abstenerse 
a la hora de votar en foros internacionales parece bastante clara y poco interpretable, los políticos libaneses la seguirán instrumentalizando para justificar decisiones partidistas. Farid Makari, del MF, tildaría la votación de "precedente en la historia diplomática libanesa que rompe con todos los valores sobre los cuales se ha fundado el Líbano" (L'OL, 13/11/2011). Dejando de lado este caso aislado, lo cierto es que tanto el PM Najib Mikati como el PR Michel Sleiman adoptan una línea centrista y evitan posicionarse en sus discursos (Gourrada, 2014: 39). En el primer año del nuevo Gobierno formado en junio de 2011 el ejecutivo consigue mantener el país en calma en términos generales (Salem, 2012: 5-7) y garantiza el cumplimiento de los compromisos internacionales (Karam, 2012: 185). Tras unas manifestaciones en mayo de 2012 en apoyo a la revuelta siria en Trípoli, de mayoría suní muy deprimida económicamente con respecto a Beirut, se produce la detención de un joven activista anti-sirio. Ello provoca mayor violencia y enfrentamiento con las fuerzas de seguridad, llevando al Ejército Libanés a desplazar efectivos al norte y abrir fuego en un control de carretera contra un shaikh (شيخ) o líder religioso suní de la región. Se suceden manifestaciones en todo el territorio con varios muertos, y varios shaikhs islamistas llaman a la violencia contra el Gobierno libanés y Hezbollah (Salem, 2012: 9).

La situación de extrema tensión e inminente desborde del conflicto al territorio libanés provoca la necesidad de hacer una llamada a la calma de forma conjunta. Conscientes de la oposición entre bloques y con la guerra civil libanesa aún presente en el imaginario colectivo la clase política pasa a la acción. La probabilidad de exportar el conflicto al Líbano era extremadamente alta si se tienen en cuenta la historia de las relaciones libano-sirias a nivel económico, social y político (Picard, 2016), la porosidad de la frontera y la influencia de integristas islámicos y salafistas en el norte del país (Lion, 2014: 221). Todos los partidos políticos están presentes en el Comité de Diálogo Nacional para firmar la Declaración de Baabda en junio de 2012, a excepción del MF de Saad Hariri y las Fuerzas Libanesas de Samir Geagea (Wählisch, 2017: 22). Esta Declaración confirmaría una disociación de los conflictos regionales que se venía aplicando de facto desde hacía un año. En el documento se insiste en "impedir que el país se sumerja en la discordia y la violencia", "otorgar un apoyo moral y material al Ejército, garante de la paz civil y símbolo de la unidad nacional" o en "promover que todas las fuerzas políticas, intelectuales y personas influyentes eviten los discursos inflamatorios". La disociación pasaba a ser por tanto una directriz a respetar en la esfera nacional, y no exclusivamente en foros internacionales en representación del Estado libanés. En resumen, se pretende "mantenerse al margen de la política de los ejes y de los conflictos regionales e internacionales con el fin de preservar los intereses superiores del Líbano" y "controlar la situación en la frontera con Siria, evitando crear una zona tapón en el Líbano que sirva de base al contrabando de armas y de soldados" (Comité de Diálogo Nacional, 2012). Durante el primer año desde la represión inicial en Siria se había mantenido el statu quo y se había evitado que el conflicto desbordara en el Líbano. Sin embargo, la Declaración de Baabda y la disociación que proclamaba en un contexto de urgencia sociopolítica no conseguirían su objetivo.

En octubre del mismo año se descubre la implicación de un diputado del MF, Okab Sakr, en una trama de tráfico de armas y fondos para los rebeldes sirios (Daher, 2018: 169). Hariri reconocería a los pocos días que Sakr era su representante oficial ante esa oposición moderada, algo que más tarde confirmarían unas grabaciones filtradas por el periódico Al-Akhbar. Este episodio no solo representaría un golpe duro para la disociación, sino que provocaría el asesinato justo el día siguiente de Wissam al-Hasan, responsable del sector de Inteligencia de las Fuerzas de Seguridad interiores que investigaba el atentado contra el PM Rafiq Hariri en 2005 (Naoum, 2014).

Tanto el PM Nagib Mikati como el PR Michel Sleiman procuraban no hablar sobre Siria y evitaban posicionarse sobre el conflicto. Esta práctica, sin embargo, no era nada común entre los principales líderes políticos libaneses, que opinaban de forma vehemente sobre su apoyo o rechazo a Assad. Michel Aoun, líder del MPL, justificaba en agosto de 2011 la represión de Assad contra lo que 
consideraba vandalismo, y criticaba cómo se instrumentalizaban los derechos humanos según el caso (Aoun en L'OL, 3/8/2011). Es el caso también de Hezbollah, que desde mayo de 2011 apoyaba públicamente a al-Assad antes incluso de que la revuelta se volviera violenta (Sullivan, 2014:11) y del MF, cuando Hariri llamaba a las comunidades árabes e internacionales a enfrentarse a Bashar Al-Assad en julio de 2012 (L'OLJ, 14/7/2012). El mismo mes, el líder del Partido Progresista Socialista del Líbano y hombre influyente de la comunidad drusa Walid Joumblatt declaraba que Assad "está destruyendo Siria" (Girard, 2012), unas declaraciones en sintonía con las del líder de las Fuerzas Libanesas Samir Geagea, que desde el principio se opuso a la represión del régimen sirio.

Estas declaraciones y el episodio de las armas se sumarían a las pruebas irrefutables por parte de oficiales de los EEUU en agosto de 2012 de que Hezbollah llevaba ya tiempo presente en Siria apoyando al régimen de Assad (Sullivan, 2014: 11-12). EI PM Nagib Mikati dimitiría en marzo de 2013, consciente del fracaso de la disociación e incapaz de poner de acuerdo a las fuerzas políticas libanesas para la renovación de figuras clave en la administración. Cabe señalar que Mikati ya intentó dejar su cargo en octubre tras saberse la trama de contrabando de armas, pero se encontró con la negativa del PR. En el momento de la dimisión de Mikati la violencia sectaria estaba cada vez más presente en el Líbano (Lebanon Support, 2016), donde los enfrentamientos entre alauís y sunís servían de espejo a lo que se vivía en Siria entre el clan alauí de Al-Assad y los rebeldes sunís, islamistas y moderados.

La disociación que no se respetaba a nivel nacional seguía sin embargo aplicándose en foros y organizaciones internacionales, donde la abstención era la única forma de evitar mayores conflictos al interior del país. Las votaciones que se suceden tanto en el Consejo de Seguridad de las NU como en la Liga Árabe o en la Organización para la Cooperación Islámica siguen la lógica de la disociación, y el Líbano se abstiene por norma general, salvo en la decisión que votaba para expulsar a Siria de la Liga Árabe. Adnan Mansour, que ya había roto con la política de disociación libanesa en aquella ocasión, volvería a dar pruebas de una sumisión total a Damasco en junio de 2013, con el incidente del bombardeo del régimen sirio en la ciudad libanesa de Arsal.

Si bien los bombardeos sirios se venían sucediendo en los aledaños de la ciudad, donde se refugiaban los rebeldes sirios, la conmoción de hacerlo en el centro hizo tomar medidas al ejecutivo. Michel Sleiman solicitó a Mansour depositar una queja formal contra Siria ante el Consejo de Seguridad de la ONU y ante la Liga Árabe. Este se negó, no solo mostrando el conflicto de autoridad en el ejecutivo libanés, sino dando signos de una sumisión total y sin condiciones del ministro libanés y su partido, Amal, hacia Siria. La disociación que sobre el papel había sido aceptada por la mayoría de las fuerzas políticas fracasaba ante los intereses partidistas de un Adnan Mansour que, en lugar de velar por los intereses del Estado que representaba, prefería salvaguardar un precioso aliado.

En la esfera internacional, la disociación en sus tres primeros años de implementación se respeta en la mayoría de las decisiones que se toman en los organismos internacionales. El ministro de AAEE, Adnan Mansour, es la única persona que no respeta esta línea entre los representantes del Estado a nivel diplomático, anteponiendo los intereses del partido Amal a los del Estado libanés. La consecuencia es la pérdida de legitimidad tanto de la diplomacia libanesa como del concepto de disociación. Tanto la llegada del nuevo ministro de AAEE Gebran Bassil en 2014 como los frecuentes cambios de PR, de PM y de ejecutivo hacen que se redefinan nuevas luchas de poder y estrategias. En este sentido, es esencial comprender las alianzas regionales, a veces frontalmente opuestas, que 
elaboran los principales partidos políticos de la diplomacia libanesa. De igual forma, se hace obligatorio entender el rol en el Líbano de dichas potencias, así como sus intereses y objetivos.

\section{Influencia de las principales potencias regionales al inicio de la disociación}

Tanto EEUU como Francia, desde los primeros años post-ocupación hasta los primeros años de la política de disociación, sufren una pérdida de protagonismo en el Líbano. Los impulsores de la Resolución 1559 en el seno del Consejo de Seguridad, que exigía la retirada de las tropas sirias del Líbano en 2004, pasan a reducir su presencia en el país del Cedro, sobre todo con la llegada de Nicolas Sarkozy al Elíseo en el año 2007 y la de Barack Obama a la Casa Blanca en 2009. Las dos potencias internacionales mantienen sin embargo reuniones frecuentes con los distintos PM y políticos del bloque del 14 de marzo (Wikileaks Saudi cables, 2009-2015). En la fase final de su mandato Sarkozy aplaudirá la política de disociación (Karam, 2012: 188) y junto a EEUU dará un paso atrás, dejando espacio a Irán y Arabia Saudí para intervenir más activamente tanto en el Líbano como en Oriente Medio (Daher, 2018: 165).

La lucha por la hegemonía regional entre Arabia Saudí e Irán ve en el Líbano un episodio más de su combate. Los dos ejercen su influencia a través de proxys, si bien con distintas estrategias. Arabia Saudí crea y financia alrededor de la familia Hariri y del MF una fuerte red clientelar, asegurándose la simpatía de un sunismo libanés (Daher, 2018: 159) consciente de la creciente influencia de los chiís en el Estado. En el Líbano sus intereses convergen sobre todo con los del MF, pero también con todo aquel que denuncie el rol de Hezbollah en el país del Cedro. La influencia se ejerce también a través de la financiación de medios de comunicación locales. Prueba de ello es la no publicación por parte de estos medios de los "Saudi cables", una serie de documentos que evidenciaban el polémico modo de proceder de la diplomacia saudí financiando medios de comunicación y grupos armados en la región (Wikileaks, 2015).

A nivel regional, en el seno del Consejo de Cooperación del Golfo y de la Liga Árabe, critican duramente la represión de Assad de las primeras manifestaciones y lideran la actividad diplomática contra el régimen sirio. Este pragmatismo y soft power a través de proxys y proselitismo wahabita caracteriza una política exterior saudí que se volverá cada vez más agresiva con la llegada al trono de Mohamed bin Salman en 2017. Durante estos primeros años de disociación, sin embargo, el perfil de los saudís es más bien bajo, utilizando su poder financiero para influir en la política y opinión pública libanesa a la vez que arman a los rebeldes sirios contra Al-Assad (Chivers y Schmitt, 2013). Esta facilidad de los saudís para influir en la política libanesa se suma a un apoyo diplomático por parte de la mayoría de los países árabes. En el caso de Irán existirá la capacidad de influir en el Líbano, pero sin el apoyo regional del que gozaban los saudís. La tesis de la "alianza de las minorías" se movilizará para justificar una política exterior agresiva y con altas pretensiones. Dicha tesis evoca la persecución que sufren las minorías de la región por parte del fundamentalismo suní a través de grupos como Al-Qaeda o Al-Nusra. Los Estados y grupos políticos que la adoptan forman parte del "Eje de la Resistencia". Los que adhieren a esta tesis construyen su identidad oponiéndose frontalmente tanto al reconocimiento de Israel como Estado como a la injerencia estadounidense en la región (Leroy, 2014: 105). La alianza de las minorías permite a Irán definirse como el agredido, lo que le permite justificar sus acciones según el principio de legítima defensa que, en palabras de José María Ridao, es el único supuesto en política internacional en que la violencia parece contar con legitimidad moral (Ridao, 2004: 12). El discurso en que el interesado se presenta como la víctima -otorgándole por tanto el derecho a la legítima defensa- será utilizado por partidos políticos como 
Hezbollah o el MPL para justificar el armamento de la organización chií al interior de la frontera libanesa ante la ocupación israelí.

Las alianzas de Irán con otros Estados son más bien escasas, entendiéndose tan solo con la Siria de Al-Assad y con Iraq, donde se asegura la simpatía de las milicias chiís y tiene un rol central a la hora de decidir nominaciones de altos cargos (Peek, 2021). La alianza con los gobernantes de estos dos Estados le permite armar por vía terrestre a su partido-milicia más valioso: Hezbollah. La organización chií ha obtenido a lo largo de los años influencia, experiencia militar y legitimidad entre buena parte de la población libanesa por su lucha contra Israel. Ni las potencias internacionales ni los Estados árabes alineados con Arabia Saudí han conseguido minar el poder de un Hezbollah que parece ya indisociable del Estado libanés, por lo menos mientras el país del Cedro siga en guerra con Israel. Prueba de ello es su presencia constante en los sucesivos ejecutivos libaneses y su papel de garante securitario en la mayoría del sur del país, en el valle de la Bekaa y en los suburbios del sur de Beirut.

Irán consigue ser "árbitro" de la política libanesa en prácticamente todos los gobiernos de la era post-ocupación en el Líbano. Con su influencia en Hezbollah y en Amal, y también en menor medida en el MPL de Aoun, con el que comparten enemigos comunes, consiguen llegar al tiers de blocage necesario para disolver el Gobierno, bloquear cualquier cuestión fundamental o impedir nominaciones de altos cargos administrativos. Cuando comienza el conflicto en 2012 Irán continúa con su influencia a través de Hezbollah y se implica en Siria en labores de información y asesoría militar. Con el tiempo, Hezbollah se involucra progresivamente en Siria, ayudando no solamente a proteger la frontera de grupos terroristas islámicos, sino recuperando territorio para el régimen de Assad.

Tras una reunión de las figuras más influyentes de Irán con el líder de Hezbollah, el shaikh Nasrallah, se decide implicar a la organización libanesa de forma total y pública el 30 de abril de 2013 (Sullivan, 2014: 14). Un mes antes, en marzo de 2013, el PM Nagib Mikati dimitía, inaugurando una etapa de once meses sin ejecutivo que acabaría en febrero de 2014, cuando Tamaam Salam conseguía reunir los votos de 124 de los 128 parlamentarios y se convertía en el nuevo PM del país. El nuevo Gobierno decide continuar con la retórica de la disociación, consciente de que el conflicto sirio tiene muchas posibilidades de seguir desbordando en el Líbano, especialmente en el Norte y en el valle de la Bekaa (Lion, 2014: 221). Gebran Bassil, del MPL y yerno de Michel Aoun, asume el rol de ministro de AAEE.

\section{La llegada del MPL a la diplomacia libanesa}

\section{Contexto regional y nueva política exterior}

La correcta comprensión y estudio de los partidos políticos que ostentan los cargos clave a nivel diplomático, como son el Ministerio de AAEE, el PM o la Presidencia de la República, permiten entender las alianzas y, por tanto, la política exterior del país del Cedro en lo sucesivo. Todos los ministros de AAEE desde 2005 habían sido chiís, por lo que debían contar con el beneplácito tanto de Hezbollah como de Amal. Faouzi Salloukh lo fue entre 2005 y 2006, y más tarde volvería a serlo 
tras los Acuerdos de Doha, de 2008 hasta 2009. Lo siguen Ali Chami en 2009 y Adnan Mansour en 2011, los dos miembros del partido Amal. Esta hegemonía acaba en 2014 cuando Gebran Bassil, miembro del principal partido cristiano en el Líbano, el MPL, se convierte en la máxima autoridad de la diplomacia libanesa.

Los primeros años post-ocupación y los primeros años de disociación habían sido turbulentos, con vacíos de poder por dimisiones de ministros en 2008 y 2011, conflictos diplomáticos en el seno del ejecutivo y una sumisión descarada a los intereses sirio-iranís por parte de Adnan Mansour. El MPL se incorpora a los puestos clave para dirigir la política exterior primero con la llegada de Bassil al Ministerio de AAEE en 2014 y después con la llegada del General Michel Aoun a la Presidencia de la República en 2016.

El mismo año en que el MPL llegaba a la cabeza de la diplomacia libanesa se producía un vacío de poder en la Presidencia de la República con el fin del mandato de Michel Sleiman. El contexto que se vive a nivel regional y que repercute en el Líbano derivaría en más de dos años sin PR, lo que tendría consecuencias en una actitud más pasiva si cabe del Líbano a nivel diplomático. El escenario regional que ha de gestionar el MPL a través de Gebran Bassil y Michel Aoun como PR en 2016 cambia profundamente a causa del pacto nuclear con Irán, la llegada de Mohamed bin Salman al trono saudí y el nuevo equilibrio de poder que se produce en Siria tras el apoyo ruso a Assad.

En julio de 2015 los EEUU de Barack Obama impulsan la creación de un acuerdo nuclear con Irán, firmado por el Estado persa, Francia, Gran Bretaña, EEUU, Alemania, Rusia y China. El objetivo es que Irán no desarrolle armas nucleares a cambio de levantar las sanciones internacionales contra la potencia del Golfo (Laferrère, 2015: 801). Este acuerdo es visto por Arabia Saudí como una traición occidental (Daher, 2018: 166) en un momento de renovación de su élite política, con la llegada de Salman ibn Abdel-Aziz al-Saoud al trono y de su hijo Mohamed bin Salman a la administración. Este último accedería al trono dos años después y guiaría la política exterior saudí con el fin de consolidarse como un actor hegemónico en la región. Lo que ciertos autores denominan la Doctrina Salman implicaba enfrentarse necesariamente a Irán en aquellos espacios donde era protagonista (Hernández, 2020).

En Siria, un Assad que se había visto superado al inicio del conflicto contaba ahora con el apoyo de Irán a través de Hezbollah y de Rusia, que se había comprometido con apoyo militar sobre el terreno. El régimen comienza a recuperar territorio en un contexto de distensión internacional contra Irán, pero de creciente agresividad saudí. La "guerra fría" que se vive entre las dos potencias regionales se plasma en el Líbano en falta de consenso para encontrar a un PR. Pese al vacío de poder presente en el país y a los numerosos atentados de extremistas islámicos en el interior de sus fronteras como respuesta a la participación de Hezbollah en Siria, el nuevo ministro de AAEE, Gebran Bassil, deja entrever cuál será la línea que adoptará el Estado libanés en lo que a política exterior se refiere.

En marzo del 2014, en el seno del Consejo de ministros de la Liga árabe, explica el derecho de su país a ejercer una resistencia legítima frente al ocupante israelí, y recuerda a los Estados árabes su responsabilidad en el mantenimiento de dicha resistencia. Este concepto implica necesariamente a Hezbollah, único garante securitario de un Estado que, según el MPL, dispone de un Ejército insuficiente y limitado. Esta tesis que entiende las armas de Hezbollah como necesarias es defendida por una amplia gama de responsables del principal partido cristiano libanés. El durante años Responsable de las relaciones diplomáticas del MPL y ex-consejero diplomático del PR Michel Aoun, Michel de Chadarevian, afirmaba en enero de 2020:

"Pero ¿qué van a hacer con las armas? Yo duermo tranquilo por la noche porque está Hezbollah, porque sé quién es nuestro enemigo a día de hoy. [...] Hoy por hoy, cualquier 
país que tenga frontera con países "simpáticos" como el nuestro, tiene que crear una especie de Hezbollah, porque es una Resistencia, no es un Ejército al uso." (Michel de Chadarevian, comunicación personal, enero de 2020)

El MPL, liderado sobre todo por Michel Aoun pero también, desde 2015, por Gebran Bassil a la cabeza del partido, adopta una estrategia singular tanto a nivel nacional como regional. Son aliados políticos de Hezbollah, con el que firmaron un memorandum of understanding en febrero del 2006, pero lo critican en el momento en que descubren que participa en la guerra siria (L'OLJ, 17/8/2013). Son también aliados de Assad, como lo muestra la defensa a ultranza de su figura durante la guerra, pero no sumisos, ya que critican que no quiera acoger a refugiados en zonas seguras y aplauden a la oposición moderada. Muestran, como los partidos políticos del 8 de marzo, un profundo antioccidentalismo y apoyan una actitud beligerante ante un Israel que ocupa su territorio, lo que les permite defender las armas de Hezbollah.

Si bien el MPL nace con una voluntad aconfesional lo cierto es que deriva hacia el discurso comunitario, defendiendo cada vez de forma más exclusiva los intereses de los cristianos en el Líbano como lo demuestra el programa de las "8 naranjas" y el interés de Aoun de definirse como "patriarca de la calle" (Lefort, 2012: 219-262). Presentándose como el defensor de los "cristianos de Oriente" en un momento en que eran cada vez más minoritarios en la región se aseguraba el respeto de las potencias occidentales, a la vez que defendía a su aliado Hezbollah alegando criterios soberanistas y a Assad como el mal menor en un contexto de aumento de extremismo islamista en Siria.

La declaración de intenciones que Bassil realiza en 2014 ante los ministros de los países árabes marcará la línea que seguirá la política exterior libanesa. En 2016 el Líbano se abstiene de votar una condena hacia Irán por parte de la Liga Árabe, lo que provoca que Arabia Saudí bloquee el contrato armamentístico "Donas", que preveía proveer al Ejército Libanés de equipamiento militar (Blin, 2016: 56). Más tarde, en la sesión 145, emite reservas sobre un texto que calificaba a Hezbollah de terrorista, y aprueba en marzo de 2016 una decisión de la misma organización regional que aplaudía las negociaciones entre Assad y la oposición siria. Cuando Michel Aoun accede a la Presidencia de la República defiende la importancia de Hezbollah en el territorio libanés al mismo tiempo que intenta establecer relaciones de cordialidad con las potencias regionales e internacionales. Prueba de ello es el primer viaje de Aoun como PR a Arabia Saudí en enero de 2017 y el recibimiento del ministro de AAEE iraní una semana después de su nombramiento.

En septiembre de 2017 Michel Aoun interviene en la Asamblea General de la ONU, proponiendo la creación de un mercado común en la zona del Levante mediterráneo para luchar contra el extremismo y la extrema pobreza. Además, insta al Alto Comisionado por los Refugiados a ayudarlos a volver a su país creando zonas seguras en Siria, en lugar de seguir financiando campos en territorio libanés (Al-Monitor, 23/8/2017). Bassil continuaría esta línea discursiva recordando que el Líbano debía gestionar la presencia de un millón de refugiados en un país que apenas contaba con cuatro millones (L'OL, 9/6/2018). Aparte de la confrontación con la comunidad internacional en lo referente a la gestión de los refugiados la nueva diplomacia libanesa, aliada de Hezbollah, sería testigo en noviembre de 2017 de un episodio que evidenciaría el nerviosismo del nuevo ejecutivo saudí. 
EI PM Saad Hariri, ciudadano saudí-libanés y frontalmente opuesto al partido-milicia chií, tomaba un vuelo a Riad y renunciaba a su cargo a través de un comunicado en el que denunciaba la injerencia de Irán en el Líbano a través de Hezbollah. Este episodio fue interpretado como una injerencia demasiado flagrante por parte de los saudís, y fue necesaria la mediación del presidente de la República de Francia, Emmanuel Macron, para hacer volver a su puesto a Saad Hariri. La ofensiva saudí, poco inteligente diplomáticamente hablando, fue denunciada por Aoun y por la población libanesa, que organizó varias protestas. El tema central que marcaría la política exterior libanesa y definiría de forma clara sus límites y margen de maniobra sería sin embargo el de la naturaleza de las relaciones que debía desarrollar con la vecina Siria.

A finales de 2017 Trump llega a la Casa Blanca, y en Siria parece difícil que Assad pueda perder la guerra (Daher, 2017). La transición política del país vecino divide a las potencias regionales y, en consecuencia, a los partidos políticos libaneses. Bassil se entrevistó con su homólogo sirio Walid alMualem en Nueva York en 2017, provocando numerosas críticas por parte del bloque del 14 de marzo. El debate sobre las relaciones que el Líbano debía mantener con Siria seguía dividiendo, como lo venía haciendo desde 2005, a los bloques del 8 y del 14 de marzo. El Líbano mantenía relaciones diplomáticas con Siria e incluso tenía un Alto Consejo libano-sirio encargado de solucionar problemas de seguridad y económicos comunes, pero no se producían reuniones oficiales entre los dos jefes de Estado.

Si ya en 2018 la victoria de Assad era evidente en el aspecto militar, sus adversarios regionales e internacionales querían una transición política donde él no participara. Hezbollah, Amal e incluso el MPL de Aoun querían que su aliado, Assad, fuera reconocido como gobernante legítimo en Siria. El bloque del 14 de marzo, en consonancia con los países occidentales y la mayoría de los países árabes, se oponía a tal reconocimiento, de importantes consecuencias a nivel internacional para Líbano. El MPL, con unos aliados y una estrategia regional tan definida, se veía preso de circunstancias que le superaban y que le impedían imponer sus intereses en la política exterior del Estado libanés.

\section{Dependencia de factores externos y encrucijada actual}

El Líbano se encuentra con dos obstáculos que se suman a otros problemas económicos estructurales, como el endeudamiento extremo y el clientelismo, y que lo precipitan hacia una grave crisis a partir de 2018. El primero es la presencia desproporcionada de refugiados en su territorio y el segundo es el estancamiento total de su economía a causa de la guerra en Siria, que supone el único Estado reconocido con el que comparten frontera terrestre. Assad les garantiza, sobre el papel, tratar ambos problemas. Por un lado, impulsar su economía dejando pasar sus productos por otras fronteras, como la jordana (con el puesto fronterizo de Nassib) o la iraquí. Por el otro, favorecer el retorno de refugiados a través de la creación de zonas seguras. El precio a pagar era reconocer su autoridad como legítimo gobernante en Siria.

El régimen sirio era consciente del delicado estado de la economía libanesa y utilizaba a su favor su posición de fuerza. Las consecuencias económicas de una tal decisión precipitarían sin embargo al Líbano hacia un punto de no retorno. Hay que recordar que los principales financiadores del país del Cedro eran tanto los países del Golfo como las principales instituciones monetarias internacionales, financiadas a su vez en gran parte por países occidentales. El precio a pagar por tal reconocimiento político era inasumible para un Estado que atravesaba un contexto crítico. En una entrevista en febrero de 2020 el Dr. Elie Hindi, responsable de las Relaciones diplomáticas de las 
Fuerzas Libanesas, segundo partido cristiano libanés en términos electorales tras el MPL y hostil a Assad, afirmaba lo siguiente:

“¿Nos beneficia hablar con Assad? En un contexto de crisis económica y necesitando apoyo
exterior, financiadores, para salir de la crisis... la financiación viene del FMI, del Banco
Mundial o del Golfo, que nos han dado dinero y apoyo, deuda, etc. Todos se opondrían a
hablar con Assad, entonces, ¿por qué hacerlo? (...) Si reconocemos su autoridad el precio
es muy alto en políticas, finanzas, en relaciones con la comunidad internacional, y también
a nivel ético, porque es un criminal." (Dr. Elie Hindi, comunicación personal, febrero de
2020)

En 2019 Aoun negaba haber pedido ayuda al FMI de cara a la opinión pública, pero al mismo tiempo aplicaba reformas para reducir el déficit satisfaciendo las exigencias del Programa CEDRE, que reunía a un conjunto de Estados financiadores en París (Xinhua, 2/8/2019). Al año siguiente el PR declaraba que la ayuda del FMI sería esencial para salir de una crisis económica (France24, $6 / 5 / 2020$ ) que había favorecido el nacimiento de un movimiento social contestatario con un inmenso apoyo civil (Rizk, 2020) llamado thawra (ثورة) o "revolución".

En octubre de 2019 surge la thawra, un movimiento popular que criticaba sobre todo la situación económica y la corrupción política, pero también elementos estructurales, como el sistema político confesional libanés (Bou Khater y Majed, 2020). La presión social haría dimitir al Gobierno del PM Saad Hariri, creando uno nuevo en enero de 2020, que pretendía ser formado por una mayoría de personas que no pertenecieran a ningún partido político, en un intento de satisfacer las demandas populares. Este "cuerpo de tecnócratas" fue nombrado por consenso del bloque del 8 de marzo mientras que el bloque de 14 de marzo no participó en su designación, lo que lleva a cuestionarse su total imparcialidad e incluso la validez del término "tecnócrata" como desideologizado. Lo cierto es que, sin embargo, Gebran Bassil tuvo que abandonar su puesto como ministro de AAEE, cerrando una era convulsa y dejando el país en una situación de impotencia internacional que no haría más que agravarse a medida que avanzaba la crisis económica, social y financiera. A este contexto se le sumaría la crisis sanitaria, consecuencia del Covid-19, que agudizaría más aún la delicada situación económica y social que sufría la población libanesa. El 4 de agosto de 2020, 2500 toneladas de nitrato de amonio explotaban en el puerto de Beirut (Rigby et al, 2020: 671-675) en lo que sería una de las explosiones no nucleares más potentes de la historia. La explosión, de gran impacto mediático, dejó más de 200 muertos, 6500 heridos, 300000 personas desplazadas y unos daños materiales catastróficos en el puerto y alrededores (Bazzi, 2020). Este episodio supuso la dimisión del ejecutivo del PM Hassan Diab, de apenas siete meses de antigüedad, inaugurando una etapa de más de un año sin Gobierno.

Países como Francia denunciarían públicamente la falta de acuerdo para nombrar un ejecutivo debido a los conflictos a la hora de ocupar los Ministerios clave (France24, 27/9/2020). Las consecuencias de no contar con un ejecutivo para gestionar una situación de crisis son catastróficas para la población libanesa, que observa un deterioro evidente de sus condiciones de vida. La devaluación de la lira libanesa frente al dólar provocaba la mayor tasa de inflación del mundo en septiembre de 2021 (Goyeneche y Khraiche, 2021), lo que implicaba una escasez de alimentos, de petróleo y de electricidad. Según las Naciones Unidas, cuatro de cada cinco libaneses viven en la actualidad bajo el umbral de la pobreza, mientras que uno de cada tres vive en situación de pobreza 
extrema (Chehayeb, 2021). En este escenario, el número de protestas aumenta, el éxodo de población al extranjero continúa y la Banque du Liban acaba con las subvenciones al petróleo.

En septiembre de 2021, el PM Najib Mikati consigue formar un nuevo ejecutivo. En un contexto en que la comunidad internacional mira con lupa al Estado libanés este parece tener pocas opciones a la hora de relacionarse internacionalmente. En este sentido, la urgencia se centra tanto en satisfacer las reformas económicas que le exigen las principales instituciones financieras mundiales como en moverse hábilmente a nivel diplomático con aquellos Estados que puedan reactivar una economía al borde del colapso total.

El primero de estos factores ya había sido una fuente de conflictos para el anterior Gobierno dirigido por Hassan Diab. La falta de consenso se produjo a la hora de aplicar medidas destinadas a combatir la corrupción, reconocer las pérdidas por parte del sector bancario, limitar el gasto en el sector público o reformar la estructura económica libanesa. Khalil Jbara, Dr. En Ciencia Política en la Lebanese American University de Beirut, analizaba las reticencias de la clase política libanesa a perder privilegios:

"Un país con una deuda tan grande no puede sobrevivir sin un programa integrado del FMI, y mientras la élite política libanesa se niegue a aceptarlo todo seguirá en caída libre. (...) Fuerza a los políticos a cambiar la forma en que tratan al sector público, le exigen reducir el tamaño del sector público. Las condiciones del FMI para el Líbano, las condiciones económicas, reducirían los privilegios de los partidos políticos, y eso es lo que les preocupa (Dr. Khalil Jbara, comunicación personal, marzo 2020)."

Por su parte, Nehmeh Azoury, Dr. en Gobernanza de Empresas en la Holy Spirit University de Kaslik analizaba las dificultades a la hora de emprender cambios estructurales en la economía libanesa:

“¿Qué decir de un país como el Líbano que tiene tanta deuda, que no tiene electricidad suficiente, que tiene una infraestructura casi inexistente? (...) O bien firmas con el FMI, firmar con el FMI te lleva a unos 25.000 millones, entre 23 y 25. Ellos ponen 9, CEDRE 11 y con algunos países árabes llegamos a 23, 25. Se hace la restructuración del sector bancario con la fusión y adquisición del sector, doce u ocho bancos como máximo, los refinanciamos porque no tienen dinero. Hacemos los grandes proyectos a través de la financiación de esos bancos. ¿Pero cómo quieres que firmemos con el FMI con la cantidad de gente que tiene una economía paralela? Si se hacen las cosas al pie de la letra se acaba la economía paralela y si se acaba esta economía hay mucha gente que se va a ver en un problema, es una cuestión muy seria." (Dr. Nehmeh Azoury, comunicación personal, marzo de 2020)

Estos problemas quedaron en evidencia en junio de 2020, cuando el director general del Ministerio de las Finanzas del Líbano y encargado de las negociaciones con el FMI, Alain Bifani, dimitía acusando al sector político y bancario libanés de falta de voluntad a la hora de aplicar las reformas (AFP, 29 de junio de 2020). Un año y medio después de este intento, y pese a que el PM Najib Mikati declaraba a principios de noviembre que el país del Cedro alcanzaría un acuerdo con el FMI a finales de mes (Reuters, 8/11/21), lo cierto es que aún no existe tal acuerdo. El Gobernador del Banco Central del Líbano declaraba que seguían existiendo diferencias a la hora de establecer el volumen exacto de pérdidas del sector financiero, algo que ya había impedido que el Estado libanés y el FMI llegaran a un acuerdo a lo largo del año 2020 (Reuters, 23/11/21).

En lo referente a las relaciones diplomáticas con Estados pudientes la situación es más compleja, y el sistema político confesional vuelve a aparecer como el origen del conflicto. En un momento en que se volvían a reforzar lazos con los países del Golfo, en mayo de 2021, el ministro de AAEE Charbel 
Wehbe realizaba unas declaraciones en las que afirmaba que dichos países eran responsables del ascenso de Daesh (Reuters, 19/5/2021). Estas declaraciones le costarían su puesto, en un intento del PM y PR de mantener a uno de los aliados económicos más necesarios del país del Cedro. A ello se le suma la publicación en octubre de 2021 de unas declaraciones del ministro de la Información George Kurdahi que, antes de ser nombrado ministro, manifestaba que los hutíes en Yemen "se defendían contra los ataques de Arabia Saudí y los Emiratos Árabes Unidos". Esta vez, Kurdahi no solo no dimitía, sino que declaraba no arrepentirse. El actual ministro de AAEE Abdullah Bou Habib sintetizaba a la perfección los conflictos de poder en el seno del ejecutivo libanés derivados del sistema confesional afirmando que las declaraciones de Kurdahi "no representaban la postura del gobierno libanés" (Agence Anadolu, 27/10/21).

Estas declaraciones provocan una crisis diplomática no solo con Arabia Saudí y los Emiratos Árabes Unidos, sino también con Kuwait y Bahréin. Los cuatro Estados hacen frente común, retiran a sus embajadores y encargados de negocios y limitan las relaciones económicas con el país del Cedro (Espinosa, 2021). No hay que olvidar que EAU y Arabia Saudí absorbían el $22 \%$ de las exportaciones libanesas en 2019 (OEC, 2019) y, junto a Kuwait, eran los principales proveedores de Inversión Directa Extranjera (IDE) en el país, llegando a proporcionar el $77 \%$ del total de la IDE en el periodo 2003-2015 (UNCTAD, 2018: 2). Saad Hariri, líder del suní MF, culpaba a Hezbollah de la crisis diplomática (Arab News, 30/10/21) mientras que el sheikh Naim Qassem, Vicesecretario General de Hezbollah, exigía a Arabia Saudí que "pidiera perdón al Líbano por su comportamiento" (Iqna, $5 / 11 / 21)$. La estrategia de confrontación y aislamiento de estos países en respuesta al rol central de Hezbollah e Irán en el Estado libanés tiene lugar en el peor contexto posible y ha sido denunciada tanto por la Liga Árabe como por Francia.

Por su parte, el presidente francés Emmanuel Macron, que ya organizó la conferencia CEDRE en 2018 y que ha recaudado fondos para el país tras la explosión de Beirut, afirmaba que organizará una nueva conferencia de financiadores cuando el programa del FMI comience a aplicarse. De igual forma, el nuevo ministro de AAEE iraní Hossein Amir-Abdollahian se comprometía a reconstruir el puerto de Beirut y a construir dos plantas eléctricas en el país (Chehayeb, 1/10/21). El abandono por parte de los países del Golfo provocará necesariamente que otros actores ocupen su espacio (Young, 2021), pero las consecuencias económicas para Líbano a corto y medio plazo serán catastróficas. Un país con unas tasas de pobreza e inflación como las del país del Cedro necesita de una sola voz a nivel diplomático para asegurarse a unos aliados regionales que son más necesarios que nunca. Esta situación de conflicto de intereses en el seno de la diplomacia libanesa no es más que otro ejemplo de la política exterior libanesa en los últimos 16 años desde la retirada siria. El confesionalismo político supone una y otra vez el origen del problema y acaba repercutiendo no solo en la credibilidad del Líbano a nivel internacional, sino en un deterioro constante de las condiciones de vida de una población libanesa cansada de sufrir las consecuencias de una terrible praxis política. 


\section{Conclusiones}

El modelo burocrático de Graham Allison muestra el proceso de negociación y las luchas de poder a la hora de desarrollar la política exterior de un Estado. En un sistema político confesional como el libanés, en el marco de una región como Oriente Medio, existen diferentes comunidades que luchan por su supervivencia y maximización de poder estableciendo relaciones con potencias regionales e internacionales. El contexto regional está profundamente polarizado y los conflictos son constantes, lo que complica el acercamiento de posturas.

La política exterior del Líbano durante la era post-ocupación sigue una línea de continuidad clara. La neutralidad positiva y la disociación se aplican precisamente en un intento de desarrollar una política exterior definida pero no protagonista. La primera no se respeta del todo, como lo muestran las dobles delegaciones diplomáticas de 2006 y 2007. Sin embargo, la diplomacia libanesa consigue con el tiempo mantener un perfil bajo, evitando ganarse enemigos poderosos (con la excepción de Israel) pero participando, si bien pasivamente, de los principales foros regionales e internacionales. Si la neutralidad positiva funciona con algunas excepciones la disociación supone un fracaso a todos los niveles. El concepto que se comienza a manejar desde 2011 es algo más complejo, aunque persiga objetivos similares.

La neutralidad positiva se centraba estrictamente en la esfera internacional, mientras que la disociación respondía a la necesidad de no trasladar un contexto revolucionario a un país que tenía muy reciente una fratricida guerra civil y una ocupación. Por ello, la disociación no implica solamente una abstención en foros internacionales y una política de cordialidad con las potencias de la región, sino que también debe evitar que los miembros del Ejecutivo se posicionen o participen activamente de los conflictos regionales. El confesionalismo es sin embargo el caldo de cultivo perfecto para incumplirla, ya que la supervivencia de cada comunidad o partido político depende de alianzas regionales e internacionales dispares. Este sistema reproduce y perpetúa de igual forma las dinámicas de poder, ya que la élite gobernante hereda de la familia el cargo de líder comunitario y/o político.

El poder e influencia de estos líderes comunitarios en el marco del confesionalismo, la estrecha dependencia entre la esfera nacional e internacional en el Líbano y una progresiva polarización del poder regional son los factores que provocan el fracaso de la disociación, lo que confirma la hipótesis que se plantea en la introducción. Las diferencias de intereses y estrategias de los partidos políticos libaneses no hacen más que agudizarse a medida que el poder regional se polariza exponencialmente alrededor de Arabia Saudí e Irán. Estos dos bloques luchan por aumentar su influencia en la región en cada escenario que se lo permita, y el frágil Estado libanés no es más que otro terreno en su batalla. El poder e influencia de los grandes líderes y partidos políticos que actúan de forma unilateral sin pensar en las consecuencias para el Estado libanés acaba dinamitando la política de disociación. Así lo evidencian las acciones de Adnan Mansour, el apoyo logístico del MF a los rebeldes sirios, la participación de Hezbollah en el conflicto vecino o el reiterado apoyo en foros internacionales del MPL a la "Resistencia" de Hezbollah, a sabiendas de las consecuencias en Relaciones Internacionales que dicho apoyo supone para el Líbano.

EI PR y el PM se esfuerzan por mantener relaciones cordiales con las principales potencias regionales e internacionales como Irán, Arabia Saudí, Francia o EEUU, intentando no alinearse con ningún bloque para no perder la confianza del otro. Realizan visitas oficiales, se dejan cortejar por las delegaciones que les recomiendan qué hacer, pero miden cada uno de sus movimientos para no provocar demasiado descontento ni entre la clase política ni entre la población. Sin embargo, tanto 
ministros de AAEE como líderes políticos con influencia y poder de movilización opinan e incitan a la acción a una población sin recursos y con un fiel arraigo a su confesión. Existe, en resumen, una contradicción evidente entre la disociación que se pretende profesar y la realidad sociopolítica libanesa.

El Mito de Sísifo sirve como metáfora a la hora de interpretar la aplicación de la neutralidad positiva y sobre todo de la disociación. En él, Zeus condena a Sísifo a empujar una roca hasta la cima de una montaña, consciente de que la roca caerá constantemente colina abajo. Existe una voluntad de llevar la roca hasta la cima de la montaña aun a sabiendas que nunca se conseguirá el objetivo. El castigo que sufre Sísifo le viene impuesto, como el confesionalismo y el contexto regional de Oriente Medio en el caso libanés, pero existe una voluntad de querer empujar la roca con la esperanza de que algún día se quede en la cima. En el caso libanés, el confesionalismo está tan sumamente respaldado por las élites comunitarias del país que no se cuestiona. De esta forma, cuando la disociación fracasa tanto a nivel nacional como internacional de forma recurrente, es más fácil para estas élites seguir empujando la roca que cuestionar los factores que hacen que caiga colina abajo. El castigo que Zeus, en una posición de poder, impone a Sísifo, está representado en este caso tanto por el sistema confesional como por la polarización regional de Oriente Medio alrededor de Irán y Arabia Saudí. La élite política libanesa es Sísifo empujando la roca, pero al mismo tiempo es Zeus, perpetuando un sistema político que protege sus privilegios. La defensa de sus privilegios no se da exclusivamente a la hora de defender el sistema político sino a la hora de asumir las pérdidas del sector financiero, lo que ha provocado un periodo de más de un año y medio sin acuerdo con el FMI. El único consenso que se da constantemente entre las élites libanesas es el de no asumir sus responsabilidades. Mientras estas élites se mantengan en el poder gracias a la estructura confesional no se podrá desarrollar ninguna política exterior coherente. De igual forma, cualquier análisis de la política exterior libanesa necesitará de un análisis del confesionalismo político y del equilibrio de poder en la región. El desborde del conflicto sirio en forma de atentados, enfrentamientos sectarios y desestabilización sociopolítica ha existido en el Líbano mientras los partidos políticos, culpándose entre ellos, obligaban a mirar el dedo en vez de la luna.

El nuevo contexto de crisis sanitaria, económica, financiera y político-social supone un ultimátum para la clase política libanesa, representada por el reciente ejecutivo del PM Najib Mikati. La población y la comunidad internacional ponen en entredicho a la élite política protegida por el confesionalismo en un momento en que es esencial para la supervivencia del Estado llegar a acuerdos con organizaciones y Estados financiadores. Los numerosos casos de conflicto de intereses entre la diplomacia libanesa, desde las dobles delegaciones diplomáticas en los primeros años hasta la reciente crisis diplomática con los países del Golfo, pasando por el desborde del conflicto sirio tras declaraciones incendiarias de los líderes políticos y religiosos libaneses, tienen claras consecuencias a nivel internacional y nacional. En un Estado ya colapsado hablar con una sola voz a nivel diplomático resulta innegociable para la recuperación económica del país, algo que implica cuestionar el poder de Zeus y no solamente empujar la roca. 


\section{Referencias}

ABOU SAMRA, Amira (2021): "The debates of methodology and methods: reflections on the development of the study of international relations", Review of Economics and Political Science, DOI: 10.1108/REPS-06-2020-0063

AFP: "La Syrie est en état de guerre civile, selon le CICR", TDG Monde, 16 de julio de 2012, disponible en https://www.tdg.ch/monde/damas-combats-violents-debut-crise/story/11378700 [consulta: 27 de noviembre de 2021]

AFP: “Crise au Liban: démission d'un haut responsible des Finances", 29 de junio de 2020, disponible en https://www.challenges.fr/monde/crise-au-liban-demission-d-un-haut-responsable-desfinances 717117 [consulta: 27 de noviembre de 2021]

AGENCE ANADOLU: “Ministre libanais de l'information: je n'ai fait de tort à personne pour présenter des excuses", 27 de octubre de 2021, disponible en https://www.aa.com.tr/fr/monde/ministrelibanais-de-linformation-je-nai-fait-de-tort-\%C3\%A0-personne-pour-pr\%C3\%A9senter-des-

excuses/2404711 [consulta: 27 de noviembre de 2021]

ALLISON, Graham T. (1971): Essence of decision: explaining the Cuban missile crisis, Boston, Little Brown.

AL-MONITOR (2017): "Aoun calls for 'Levantine common market', safe return of Syrian refugees", 23 de septiembre de 2017, disponible en https://www.al-monitor.com/originals/2017/09/lebanonaoun-levantine-market-return-syria-refugees-abbas.html [consulta: 27 de noviembre de 2021]

ANDEWEG, Rudy B. (2000): “Consociational democracy”, Annual Reviews Political Science, no 3, pp. 509-36. DOI: 10.1146/annurev.polisci.3.1.509

ARAB NEWS (2021): “Hezbollah responsible for Lebanon's rift with Saudi Arabia, says former PM Hariri", 30 de octubre de 2021, disponible en https://www.arabnews.com/node/1957956/middleeast [consulta: 27 de noviembre de 2021]

BAZZI, M. (2020): "The corrupt political class that broke Lebanon", Foreign Affairs, disponible en https://www.foreignaffairs.com/articles/lebanon/2020-08-14/corrupt-political-class-broke-

lebanon [consulta: 27 de noviembre de 2021]

BLIN, Louis (2016): "L'émancipation contrainte de la politique étrangère saoudienne", Politique étrangère, no 2, pp. 49-61. DOI: 10.3917/pe.162.0049

BOU KHATER, Lea y MAJED, Rima (2020): “Lebanon's 2019 October revolution: who mobilized and why?", The Asfari Institute for Civil Society and Citizenship, American University of Beirut, disponible en http://www.activearabvoices.org/uploads/8/0/8/4/80849840/leb-oct-rev - v.1.3-digital.pdf [consulta: 27 de noviembre de 2021]

CAMAU, Michel (2012): “Un printemps arabe? L'émulation protestataire et ses limites", L'année du Maghreb. DOI: 10.4000/anneemaghreb.1383

COMItÉ DE DIÁLOGO NACIONAL (2012): "Declaración de Baabda", disponible en https://www.voltairenet.org/article181968.html [consulta: 27 de noviembre de 2021]

CONSTITUCIÓN DEL LÍBANO (1990): disponible en

http://idpbarcelona.net/docs/recerca/mediterranea/fichas/libano/constitucion.pdf [consulta: 27 de noviembre de 2021]

CHEHAYEB, Kareem: "UN urges Lebanon to implement reforms as extreme poverty grows", AlJazeera, 1 de octubre de 2021, disponible en https://www.aljazeera.com/news/2021/10/1/unlebanon-reforms-extreme-poverty-economic-crisis [consulta: 27 de noviembre de 2021] 
CHIVERS, C.J y SCHMITT, E. (2013): "Saudis step up help for rebels in Syria with Croatian arms", The New York Times, disponible en https://www.nytimes.com/2013/02/26/world/middleeast/in-shiftsaudis-are-said-to-arm-rebels-in-syria.html?pagewanted=all [consulta: 27 de noviembre de 2021]

CHOUCAIR, Walid (2006): “Retirada siria del Líbano" en RIBERA I PINJOL, J. y FLORENSA PALAU, S. (coords.): Med. 2006: el año 2005 en el espacio Euromediterráneo, IEMed, pp. 35-39.

DAHER, Joseph (2017): "Syrie: quelle reconstruction possible sous le régime Assad?", The conversation, disponible en https://theconversation.com/syrie-quelle-reconstruction-possiblesous-le-regime-assad-88494 [consulta: 27 de noviembre de 2021]

DAHER, Aurélie (2018): “Parrainages régionaux et polarisations belligènes: la rivalité entre l'Iran et I'Arabie saoudite au Liban", Critique Internationale, vol. 3, no 80, pp. 155-177. DOI: 10.3917/crii.080.0155

EL-EZZI, Ghassan (2008): “Décrispation au Liban: en attendant”, Confluences Méditerranée, no 67, pp. 69-77. DOI: $10.3917 /$ come.067.0069

ESPINOSA, Ángeles (2021): “Cuatro países del Golfo abren una crisis diplomática con Líbano por las declaraciones de un ministro sobre la guerra de Yemen", El País, 30 de octubre de 2021, disponible en https://elpais.com/internacional/2021-10-30/cuatro-paises-del-golfo-abren-una-crisisdiplomatica-con-libano-por-las-declaraciones-de-un-ministro-sobre-la-guerra-de-yemen.html [consulta: 27 de noviembre de 2021]

FRANCE24 (2020): “La ayuda del FMI al Líbano es un 'paso obligado' para salir de la crisis, dice su presidente", France24, 6 de mayo de 2020, disponible en https://www.france24.com/es/20200506la-ayuda-del-fmi-al-I\%C3\%ADbano-es-un-paso-obligado-para-salir-de-la-crisis-dice-su-presidente [consulta: 27 de noviembre de 2021]

FRANCE24 (2020): "Emmanuel Macron: "La classe politique libanaise a trahi son engagement", France24, 27 de septiembre de 2020, disponible en https://www.france24.com/fr/20200927-endirect-suivez-la-conf\%C3\%A9rence-de-presse-de-macron-sur-le-liban[consulta: 27 de noviembre de 2021]

GIRARD, Renaud (2012): "Les Libanais redoutent un durcissement du Hezbollah", Le Figaro, 24 de julio de 2012, disponible en https://www.lefigaro.fr/international/2012/07/24/0100320120724ARTFIG00609-les-libanais-redoutent-un-durcissement-du-hezbollah.php [consulta: 27 de noviembre de 2021]

GOURRADA, Raphaël (2013): “Comment lire la politique étrangère libanaise à l'heure de la crise syrienne?", en BERTHELOT, Pierre (coord.): Théorie et pratique des relations internationales au Moyen-Orient, Paris, Les Cahiers du CCMO, Numéro 5, Éditions du Cygne, pp. 27-40, disponible en http://www.editionsducygne.com/editions-du-cygne-theorie-relations-internationales.html

[consulta: 27 de noviembre de 2021]

GOYENECHE, Ainhoa y KHRAICHE, Dana: “Lebanon's inflation rises to highest globally as crisis deepens", Bloomberg, 21 de septiembre de 2021, disponible en https://www.bloomberg.com/news/articles/2021-09-21/lebanon-s-inflation-rises-to-highestglobally-as-crisis-deepens [consulta: 27 de noviembre de 2021]

HALLIDAY, Fred (1994): Rethinking International Relations, Vancouver, University of British Columbia Press. 
HAMATI-ATAYA, Innana (2019): "Behavioralism", International Studies Association and Oxford University Press, DOI: 10.1093/acrefore/9780190846626.013.376

HERNÁNDEZ, David (2020): El reino de Arabia Saudí y la hegemonía de Oriente Medio, Madrid, La Catarata.

HUBBARD, Ben (2015): "Cables released by Wikileaks reveal Saudis checkbook diplomacy", The New York Times, disponible en https://www.nytimes.com/2015/06/21/world/middleeast/cablesreleased-by-wikileaks-reveal-saudis-checkbook-diplomacy.html [consulta: 27 de noviembre de 2021]

IQNA (2021): "Hezbollah Official demands Saudi apology", 5 de noviembre de 2021, disponible en https://iqna.ir/en/news/3476342/hezbollah-official-demands-saudi-apology [consulta: 27 de noviembre de 2021]

JALKH, Jeanine (2018): "Bassil part en guerre contre le HCR », L'OLJ, disponible en https://www.lorientlejour.com/article/1119987/bassil-part-en-guerre-contre-le-hcr.html

[consulta: 27 de noviembre de 2021]

JORDÁN, Javier (2013): “Enfoques teóricos de los estudios estratégicos”, en JORDÁN, Javier (coord.): Manual de estudios estratégicos y seguridad internacional, Madrid, Plana y Valdés, pp. 15-44.

KARAM, Karam (2012): "The Fragile Balance in Lebanon: Domestic Tension and Foreign Pressure", Mediterranean Yearbook 2012, IEMed, pp. 184-189, disponible en https://www.iemed.org/wpcontent/uploads/2021/02/The-Fragile-Balance-in-Lebanon-Domestic-Tension-and-Foreign-

Pressure.pdf [consulta: 27 de noviembre de 2021]

KOCHUYT, Thierry (2004): “La misère du Liban: une population appauvrie, peu d'État et plusieurs solidarité souterraines", Revue Tiers Monde, vol. 3, no 179, pp. 515-537. DOI: 10.3917/rtm.179.0515 L'OL (2011): “Aoun: II n'y a pas de répression en Syrie et les droits de l'homme sont un label commercial brandi par l'Occident", L'OLJ, 3 de agosto de 2011, disponible en https://www.lorientlejour.com/article/715852/Aoun \%253A II n\%2527y a pas de repression en Syrie et les droits de 1\%2527homme sont un label commercial brandi par 1\%25270ccid ent.html [consulta: 27 de noviembre de 2021]

L'OL (2011): "Mikati : J'essaie de mettre un mur entre le Liban et les événements en Syrie", L'OLJ, 17 de agosto de 2011, disponible en https://www.lorientlejour.com/article/717924/Mikati \%253A Jessaie de mettre un mur entre le Liban et les evenements en Syrie.html [consulta: 27 de noviembre de 2021]

L'OL (2011): “L'opposition exprime sa honte après le rejet par Beyrouth de la résolution arabe sur la Syrie", L'OLJ, 13 de noviembre de 2011, disponible en https://www.lorientlejour.com/article/731325/Lopposition exprime sa honte apres le rejet pa

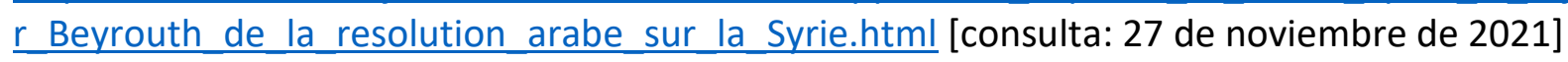

L'OL (2012): "Treimsa : Hariri et Siniora se déchaînent contre le régime Assad", L'OLJ, 14 de julio de 2012, disponible en https://www.lorientlejour.com/article/768298/Treimsa\%2B\%253A Hariri et Siniora se dechain ent contre le regime Assad.html [consulta: 27 de noviembre de 2021]

L'OL (2013): “Aoun contre l'intervention du Hezbollah en Syrie”, L'Orient-le-Jour, 17 de agosto de 2013, disponible en https://www.lorientlejour.com/article/828382/aoun-contre-lintervention-duhezbollah-en-syrie.html [consulta: 27 de noviembre de 2021]

LAFERRÈRE, Armand (2015): “Le Moyen-Orient après I'accord nucléaire iranien”, Commentaire, vol. 4, no 152, pp. 801-808. DOI: 10.3917/comm.152.0801 
LEBANON SUPPORT (2016): “Crisis and Control. (In)Formal Hybrid Security in Lebanon”, Netherlands Organisation for Scientific Research, Beirut. DOI: 10.28943/CSKC.003.00018

LEFORT, Bruno (2012): "Représentations du leadership et mémoires vives chez les militants aounistes" en MERMIER, Franck y MERVIN, Sabrina (dirs.): Leaders et partisans au Liban, Hommes et société, Paris, Karthala, pp. 219-262. DOI: 10.3917/kart.mermi.2012.01.0219

LEROY, Didier (2014): "L'axe de la résistance dans le feu syrien: perspective du Hezbollah", Confluences Méditerranée, 2014/2 n.89, disponible en https://www.cairn.info/revue-confluencesmediterranee-2014-2-page-105.htm [consulta: 27 de noviembre de 2021]. DOI: https://doi.org/10.3917/come.089.0105

LIJPHART, Arendt (1969): “Consociational democracy”, World Politics, vol. 21, pp. 207-225. DOI: $\underline{10.2307 / 2009820}$

LION, Javier (2014): “Líbano y Siria: entre la disociación y el desbordamiento”, Revista CIDOB d’Afers Internacionals, $\quad$ n. 108, pp.213-235, disponible en https://www.raco.cat/index.php/RevistaCIDOB/article/view/285538 [consulta: 27 de noviembre de 2021]

NAOUM, Rita (2014): Constructivism and Lebanon's Foreign policy following Syria's uprising [Tesis doctoral], Lebanese American University, School of Arts and Sciences, DOI: https://doi.org/10.26756/th.2014.43.

NORTON, Augustus Richard (2007): "The role of Hezbollah in Lebanese domestic politics", The International Spectator, vol. 42, no 4, pp. 475-491. DOI: 10.1080/03932720701722852

----- (2014): Hezbollah: a short history, Princeton University Press.

OBSERVATORY OF ECONOMIC COMPLEXITY (OEC) (2019): “Lebanon”, disponible en https://oec.world/en/profile/country/lbn [consulta: 27 de noviembre de 2021]

PEEK, Andrew L. (2021): "How to normalize the Iraq-Iran relationship", Atlantic Council, disponible en https://www.atlanticcouncil.org/blogs/menasource/how-to-normalize-the-iraq-iranrelationship/ [consulta: 27 de noviembre de 2021]

PICARD, Elizabeth (2008): “Liban, un équilibre précaire”, Questions internationales, septiembreoctubre 2008, no 33, La Documentation française, pp. 89-99.

----- (2016): Liban-Syrie, intimes étrangers: un siècle d'interactions sociopolitiques, Arles, Sindbad actes sud.

RABI, Uzi, (2009): "Conflit entre sunnites et chiites: le Moyen-Orient à la veille d'une guerre entre Árabes et iraniens?", Outre-Terre. DOI: 10.3917/oute.022.0189

REUTERS (2021): "Lebanon foreign minister quits after angering Gulf allies", 19 de mayo de 2021, disponible en https://www.reuters.com/world/middle-east/lebanons-foreign-minister-asks-quitafter-comments-strained-gulf-ties-2021-05-19/ [consulta: 27 de noviembre de 2021]

REUTERS (2021): "Lebanon has yet to give IMF figure for financial losses, central bank governor says", 23 de noviembre de 2021, disponible en https://www.reuters.com/markets/us/lebanon-hasyet-give-imf-figure-financial-losses-central-bank-governor-says-2021-11-23/ [consulta: 27 de noviembre de 2021] 
REUTERS (2021): "Lebanon's PM says IMF talks progressing well", 8 de noviembre de 2021, disponible en https://www.reuters.com/world/middle-east/lebanons-pm-says-imf-talksprogressing-well-2021-11-08/ [consulta el 26 de noviembre de 2021]

RIDAO, José María (2004): La paz sin excusa: sobre la legitimación de la violencia, Barcelona, Kriterios Tusquets.

RIGBY, S. E.; LODGE, T. J.; ALOTAIBI, S.; BARR, A. D.; CLARKE, S. D.; LANGDON, G. S. y TYAS, A. (2020): "Preliminary yield estimation of the 2020 Beirut explosion using video footage from social media", Shock Waves, no 30, pp. 671-675. DOI: 10.1007/s00193-020-00970-z

RIZK, Sibylle (2020): “Plus d'un an après la révolte des Libanais, le système de pouvoir en place n'a pas cédé un pouce", Confluences Méditerranée, vol. 4, o 115, pp. 75-88. DOI: $\underline{10.3917 / \text { come.115.0077 }}$

SALLOUKH, Bassel F. (2008): "The art of the impossible: the foreign policy of Lebanon" en Korany, B. y Hilal Dessouki, Ali E. (eds.): The Foreign Policies of Arab States: The Challenge of Globalization, American University in Cairo Press, pp. 283-317.

SALEM, Paul (2012): "Can Lebanon survive the Syrian crisis?", Carnegie Middle East Center, The Carnegie Papers, disponible en https://www.jstor.org/stable/resrep12901?seq=9\#metadata info tab contents [consulta: 27 de noviembre de 2021]

SULLIVAN, Marisa (2014): "Hezbollah in Syria", Institute for the study of war, Middle East security Report 19, April 2014, disponible en https://www.jstor.org/stable/pdf/resrep07896.pdf?refreqid=excelsior\%3A9e1750ed3f351a231b5 9cf4eb6e842e4 [consulta: 27 de noviembre de 2021]

TAWIL KURI, Marta (2016): Siria: poder regional, legitimidad y política exterior, 1996-2015, EI Colegio de México.

TAGHRIB NEWS: "Lebanon is against Syria's membership suspension", Taghrib News, 15 de noviembre del 2011, disponible en http://www.taghribnews.com/en/news/71165/lebanon-isagainst-syria-s-membership-suspension [consulta: 27 de noviembre de 2021]

UN (2004): “1559 Resolution", UN, disponible en https://www.un.org/press/en/2004/sc8181.doc.htm [consulta el 27 de noviembre de 2021]

UNCTAD (2018): Investment Policy Review: Lebanon, disponible en https://unctad.org/system/files/official-document/diaepcb2017d11 en.pdf [consulta: 27 de noviembre de 2021]

VLOEBERGHS, Ward (2012): "The Hariri Political Dynasty after the Arab Spring", Mediterranean Politics, vol. 17, no 2, pp. 241-248. DOI: 10.1080/13629395.2012.694046

WÄHLISCH, Martin (2017): "The Lebanese National Dialogue, Past and Present Experience of Consensus-Building", National Dialogue handbook case study, Berlin, Berghof Foundation, disponible en www.berghof-foundation.org/publications/national-dialogue-handbook [consulta: 27 de noviembre de 2021]

WIKILEAKS (2015): "Saudi cables", Wikileaks, disponible en https://wikileaks.org/saudi-cables/ [consulta: 27 de noviembre de 2021]

XINHUA (2019): "Presidente libanés niega plan para pedir ayuda a FMI", Xinhuanet, disponible en http://spanish.xinhuanet.com/2019-08/03/c 138279581.htm [consulta: 27 de noviembre de 2021]

YOUNG, Michael (2006): "Un sommet arabe? Non, une mascarade", The Daily Star-Beyrouth, disponible en https://www.courrierinternational.com/article/2006/04/06/un-sommet-arabe-nonune-mascarade [consulta: 27 de noviembre de 2021] 
YOUNG, Michael (2021): "Kingdom come", Carnegie Middle East Center, 12 de octubre de 2021, disponible en https://carnegie-mec.org/diwan/85544 [consulta: 27 de noviembre de 2021]

\section{Entrevistas}

Entrevista del autor con el Sr. Michel de Chadarevian, responsable de Relaciones diplomáticas del Movimiento Patriótico Libre y ex-consejero diplomático del PR Michel Aoun, a 20 de enero de 2020.

Entrevista del autor con el Dr. Elie Hindi, responsable de Relaciones diplomáticas de las Fuerzas Libanesas, a 13 de febrero de 2020.

Entrevista del autor con el Dr. Khalil Jbara, Dr. en Ciencias Políticas de la Lebanese University of Beirut, a 28 de febrero de 2020.

Entrevista del autor con el Dr. Nehmeh Azoury, Dr. en Gobernanza de empresas de la Holy Spirit University de Kaslik, a 5 de marzo de 2020. 